\title{
Integrins in Cell Migration
}

\author{
Anna Huttenlocher ${ }^{1}$ and Alan Rick Horwitz ${ }^{2}$ \\ ${ }^{1}$ Departments of Pediatrics and Medical Microbiology and Immunology, University of Wisconsin-Madison, \\ Madison, Wsconsin 53706 \\ ${ }^{2}$ Department of Cell Biology, University of Virginia School of Medicine, Charlottesville, Virginia 22908 \\ Correspondence: Horwitz@virginia.edu; huttenlocher@wisc.edu
}

\begin{abstract}
Integrin-based adhesion has served as a model for studying the central role of adhesion in migration. In this article, we outline modes of migration, both integrin-dependent and -independent in vitro and in vivo. We next discuss the roles of adhesion contacts as signaling centers and linkages between the ECM and actin that allows adhesions to serve as traction sites. This includes signaling complexes that regulate migration and the interplay among adhesion, signaling, and pliability of the substratum. Finally, we address mechanisms of adhesion assembly and disassembly and the role of adhesion in cellular polarity.
\end{abstract}

\section{IMPORTANCE OF MIGRATION}

$T^{\text {he }}$ he past two decades have witnessed enormous progress in understanding integrinmediated cell migration. Integrins are implicated in cellular migrations in many contexts. These include leukocyte trafficking in immune surveillance, movements that mediate tissue regeneration and repair, and migration during embryonic morphogenesis, e.g., the movement of cell sheets during gastrulation and the migration of stem cells from epithelia in which they are born to distant targets (Webb et al. 2002; Ridley et al. 2003; Friedl and Wolf 2010). Many human diseases including cancer and inherited immunodeficiency disorders have been associated with altered integrin-mediated adhesion and migration. There has therefore been strong interest in understanding and potentially targeting integrin-mediated migration to treat human disease. However, understanding cell migration is challenging because it is the result of transient, localized adhesion and signaling. In this article, we focus on how integrins regulate cell migration and how formation and disassembly of integrin-mediated adhesions are regulated temporally and spatially during directed cell migration.

\section{Modes of Migration}

Cell migration requires the dynamic interaction between a cell and the substratum on which it is attached and over which it migrates. Distinct modes of migration contribute to diverse types of cell movements; they range from the movement of single cells to collective cell migration, where intercellular interactions are retained and groups of cells move coordinately (Friedl and Wolf 2010). The movement of individual cells is increasingly described as either "mesenchymal" or "amoeboid." However, these terms

Editors: Richard O. Hynes and Kenneth M. Yamada

Additional Perspectives on Extracellular Matrix Biology available at www.cshperspectives.org

Copyright (C) 2011 Cold Spring Harbor Laboratory Press; all rights reserved; doi: 10.1101/cshperspect.a005074

Cite this article as Cold Spring Harb Perspect Biol 2011;3:a005074 
are poorly defined, seem to be extremes of a continuum, and can be confusing because nonmesenchymal cells can undergo mesenchymal migration and an amoeba-like Dictyostellium can undergo mesenchymal-like migration.

At one extreme, mesenchymal cell migration is characterized by single cell motility and a multistep cycle of protrusion, adhesion formation, and stabilization at the leading edge followed by cell body translocation and release of adhesions and detachment of the cell's rear (Abercrombie et al. 1971; Heath and Dunn 1978; Huttenlocher et al. 1995; Lauffenburger and Horwitz 1996; Ridley et al. 2003). Motile fibroblasts and some cancer cells show organized adhesion structures and can exert substantial contractile forces on the ECM. Mesenchymal migration in three-dimensional tissues is associated with the degradation of ECM and regulated extracellular proteolysis (Friedl and Wolf 2010). Amoeboid migration lies at the other extreme and is characterized by gliding and rapid migration; it is the primary mode of migration for highly motile cells including neutrophils, dendritic cells, and lymphocytes. These cells exert relatively weak integrin-mediated traction forces on the surrounding substrate and can even be integrin-independent (Lammermann et al. 2009; Friedl and Wolf 2010). For example, migration of dendritic cells in interstitial tissues does not require integrins, which are used for motility over some 2-D surfaces (Lammermann et al. 2008). Amoeboid cells generally do not form readily visualized adhesive structures; but larger adhesion complexes can be induced by inflammatory stimuli, such as TNF $\alpha$ that impair cell motility and induce leukocyte stopping and retention (Fuortes et al. 1994; Lokuta and Huttenlocher 2005). Although integrin-induced traction forces are generally weak during amoeboid cell motility, under many conditions weak integrin-mediated adhesions likely modulate the fast gliding motility of amoeboid cells. An extreme kind of integrin-independent 3-D migration can be shown by amoeboid cells including dendritic cells; in this mode, the cells move via a blebbing type of migration driven by cortical actin cytoskeletal tension (Lammermann et al. 2008).
Thus, cells can use both integrin-dependent and independent mechanisms to orchestrate their movement through changing environments until they reach their final destination. The ability of cells to adapt and switch from integrin-dependent to integrin-independent modes of migration in the context of tumor cell migration and invasion makes the therapeutic targeting of integrins to treat diseases such as tumor invasion and metastasis challenging (Friedl and Wolf 2010).

\section{Integrins}

Integrins are the major and best-characterized trans-membrane receptors that mediate dynamic interactions between the extracellular matrix and the actin cytoskeleton during cell motility (Fig. 1). Integrins are $\alpha \beta$ heterodimers with a large extracellular domain that binds the extracellular matrix (ECM) and links to the actin cytoskeleton through a short cytoplasmic tail (Hynes 2002). Binding specificity is determined by the extracellular domain of integrins that recognize diverse matrix ligands including fibronectin (e.g., $\alpha 5 \beta 1, \alpha v \beta 3, \alpha 4 \beta 1$ ), collagen (e.g., $\alpha 1 \beta 1, \alpha 2 \beta 1$ ), and laminin (e.g., $\alpha 2 \beta 1$, $\alpha 3 \beta 1, \alpha 6 \beta 1$ ). Cell surface receptors including the Ig superfamily members ICAM-1 $(\alpha \mathrm{L} \beta 2$, $\alpha \mathrm{M} \beta 2)$ or VCAM-1 $(\alpha 4 \beta 1)$ are also recognized by integrins. In general, integrins bind to specific motifs within the matrix protein; for example, nine different integrins can bind to fibronectin and recognition is usually through the central cell-binding domain (Arg-Gly-Asp [RGD] motif). Therefore, cells adherent to fibronectin have matrix-induced adhesions that contain many different integrins that can differentially affect adhesion dynamics and cell motility. For example, on fibronectin $\alpha 5 \beta 1$ integrin-mediated adhesions are more dynamic than $\alpha v \beta 3$-mediated adhesions that are associated with more persistent migration (reviewed in Truong and Danen 2009; Huveneers and Danen 2009). Changing the integrin repertoire can correlate with changes in migration including more invasive phenotypes; for example, expression of $\alpha v \beta 3$ integrin on melanomas correlates with tumor invasion (Seftor et al. 1992) 


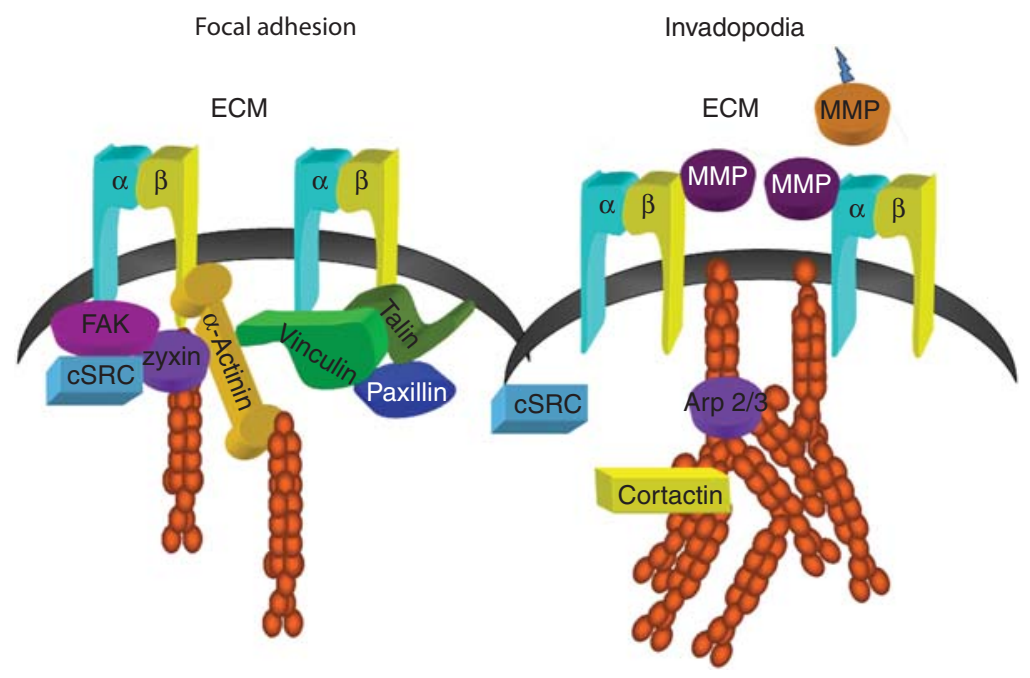

Figure 1. Focal adhesions and invadopodia. Schematic showing some major compositional and structural differences between focal adhesions and invadopodia. The linkage from integrin to actin could occur through talin or $\alpha$-actinin in focal adhesions. A large number of signaling complexes are also implicated in adhesive signaling. In general, they reside in large complexes, which are not shown. (Figure is courtesy of Christa Cortesio.)

and the $\alpha 2 \beta 1$ integrin with metastasis of rhabdomyosarcoma (Chan et al. 1990).

To migrate, integrin-mediated adhesions dynamically form and turn over, and the polarized assembly and disassembly of adhesions are essential for optimum cell speed and directional persistence (Fig. 2). In 2-D systems, cell migration speed is maximum at intermediate levels of cell-substratum adhesion where both adhesion formation and release are efficient (DiMilla et al. 1993). Density of ligand, receptor concentration, ligand-binding affinity and cytoskeletal associations are all key determinants of cell migration speed (Huttenlocher et al. 1996; Palecek et al. 1997). Optimum cell speed occurs at intermediate levels of expression of $\alpha 5 \beta 1$ or $\alpha 2 \beta 1$ integrins or intermediate concentrations of ligand, including fibronectin or collagen. In general, in most cell types, there is an intermediate cell-substratum adhesiveness that supports maximum migration (reviewed in Huttenlocher et al. 1995; Lauffenburger and Horwitz 1996; Palecek et al. 1997; Gupton and Waterman-Storer 2006). This optimum in "adhesiveness" is also seen in 3-D migration as well as contributions of matrix pliability for some matrices (Zaman et al. 2005, 2006, 2007) but not for others (Doyle et al. 2009).

\section{INTEGRINS IN MIGRATION - THE BASICS}

\section{Traction}

Adhesion serves two major functions in migration. It generates traction by linking the extracellular substratum to actomyosin filaments, and it organizes the signaling networks that regulate migration and other cellular processes including proliferation, gene expression, and cell survival. The linkage between the extracellular matrix and actin has been known for over 30 years based on electron microscopic and fluorescence colocalization studies (Lazarides and Burridge 1975; Izzard and Lochner 1976; Heath and Dunn 1978). Although several molecules are implicated, the precise molecular linkages that form between integrin and the actin cytoskeleton remain unclear. The most likely candidates include talin, vinculin, and $\alpha$-actinin. Cellular forces transmitted to the substratum through the integrin-actin linkage system have a profound effect on cell migration. On the 


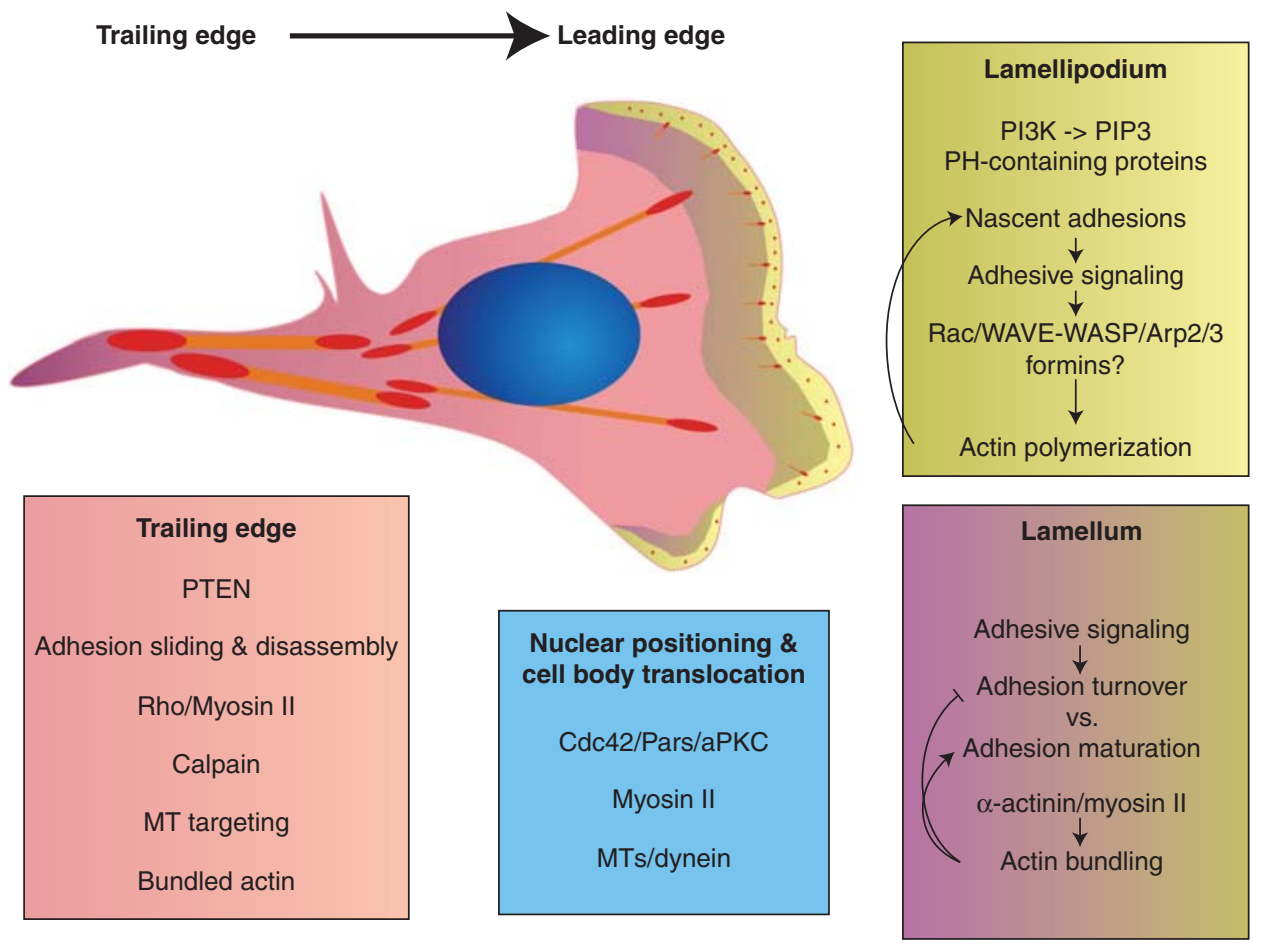

Figure 2. Polarity in migrating cells. The schematic shows the localization and functions that establish front-to-back polarity. In gradient sensing, local PIP3 is produced at the leading edge by polarized distributions of PI3 kinase and PTEN (Kölsch et al. 2008; Swaney et al. 2010). At the cell front, adhesions form and turn over and signal to Rho GTPases; these signals lead to actin polymerization via formins and Arp $2 / 3$ as well as assembly of new adhesions. Myosin II and microtubules contribute to polarity, the latter occurring through aPKC/PAR complexes. The rear retracts and adhesions release in response to force and other activities like calpain. (Figure is courtesy of Miguel Vicente-Manzanares.)

one hand, they regulate the rate of protrusion. In the absence of an adhesion, membrane resistance to actin polymerization at the leading edge would lead to retrograde actin flow (Mitchison and Cramer 1996). Likewise, contraction of actomyosin filaments in the cell front also produces retrograde flow. Because the protrusion rate is the difference between the rate of actin polymerization and the retrograde flow rate, adhesions produce more rapid protrusion by inhibiting retrograde flow. In addition, adhesion maturation and the signals generated by the adhesion are likewise regulated by the tension on the adhesion (Giannone et al. 2007; Choi et al. 2008).

The shunting of actin force to the substratum via adhesions leads to the notion that adhesions serve as a molecular clutch. It is now clear that the molecules that comprise the clutch do not efficiently transmit all of the force to the substratum; but instead there is a molecular slippage (Brown et al. 2006; Hu et al. 2007). This is seen by the movement of adhesion molecules with actin during retrograde flow (Brown et al. 2006; Guo et al. 2007; Hu et al. 2007). Some adhesion components like $\alpha$ actinin move with a velocity similar to actin, integrin generally does not move, and other components move at intermediate rates. $\mathrm{Al}$ though much of the slippage occurs within adhesions, it is possible that the integrin-ligand interaction could be weak as well and slip at that level. Finally, a highly pliable substratum could move under contractile forces. Thus, a complex 
feedback loop connects adhesion, contraction, and pliability (Vicente-Manzanares et al. 2009). Tension on adhesions results in their maturation and is presumed to change the signaling properties, which in turn affect adhesion and tension. The efficiency of the linkage, in turn, along with pliability, dictates the effect of tension.

\section{Integrin Signaling}

Ligand binding induces integrin clustering that forms multiprotein complexes comprised of intracellular signaling and adaptor proteins that connect to the actin cytoskeleton. The affinity of integrin for its ligands is regulated by intracellular signaling that leads to integrin activation (reviewed in Shattil et al. 2010). Activation of integrins is critical for leukocyte transmigration and polarized cell motility, where $\alpha v \beta 3$ integrin activation is observed at the leading edge of cells (Kiosses et al. 2001). Key regulators of activation include talins and kindlins, two proteins that bind the $\beta 1$ and $\beta 2$ integrin cytoplasmic domains (Moser et al. 2008; Shattil et al. 2010). Talin, in turn, is regulated by the small GTPase Rap1 through an interaction with the Rap1-GTPinteracting adaptor molecule (RIAM) (Han et al. 2006).

Integrin-containing adhesions function as signaling centers orchestrating a network of signaling pathways that mediate cell migration. The Rho GTPases act as a convergence point for these networks and function to regulate actin polymerization and dynamics as well as adhesion itself (for reviews see Ridley et al. 2003; Abram and Lowell 2009; Huveneers and Danen 2009). Signaling by adhesions can be highly localized and thereby drive the polarized phenomena that comprise migration (Fig. 2). For example, localized activation of PKA induced by integrin ligation is an early step in directed cell migration (Lim et al. 2008). In addition, the adhesions in protrusions, particularly near the leading edge, are thought to regulate actin polymerization and thereby localize protrusion (Galbraith et al. 2007; Choi et al. 2008). In this way, the transient localized activation of intracellular signaling regulated by integrins contributes to temporal and spatial activation that mediates polarized cell migration. Dissecting these localized signaling changes in highly motile cells, particularly in vivo, is a challenge that requires live cell imaging of appropriate biosensors (Hodgson et al. 2008).

\section{Adhesion Structures that Drive Cell Migration}

Integrin-based adhesions are highly complex structures with over $\sim 150$ different associated molecules (Fig. 1) (Geiger et al. 2009; Geiger and Yamada 2011). Depending on the cell and its environment, they appear in a variety of sizes, morphologies, and locations. So far, a robust categorization, based on composition or function, has not been described. Part of the challenge is to identify stable intermediate endpoints within a continuum of maturation. Although all of these adhesions are often lumped into a single class and categorized as focal adhesions, definite subclasses can now be identified, e.g., nascent adhesions, focal complexes, focal adhesions, and fibrillar adhesions (Zaidel-Bar et al. 2004; Vicente-Manzanares et al. 2009; Geiger and Yamada 2011), the last of which will not be discussed here because they are not typically present in migrating cells. Nascent adhesions and focal complexes lie at one extreme and are small, dynamic, and dotlike adhesions that reside near the leading edge in protrusions and mediate signals that promote actin polymerization (Alexandrova et al. 2008; Choi et al. 2008). The nascent adhesions reside in the lamellipodium and are hard to visualize by conventional, wide field light microscopy. Focal complexes, which can be formed by expressing a constitutively activated Rac, are larger than nascent adhesions and are myosin II-dependent (Ridley et al. 1992; Rottner et al. 1999). They are prominent in highly motile cells like leukocytes that form less organized adhesions (reviewed in Huttenlocher et al. 1995; Lauffenburger and Horwitz 1996). There is generally an inverse correlation between the size and organization of focal adhesions and cell migration speed (Lauffenburger and Horwitz 1996). Podosomes and invadopodia 
are entirely different classes of migration-related adhesions; they differ significantly in organization and composition from focal adhesions (Linder 2007).

\section{Focal Adhesions}

Focal adhesions, the best characterized of the cell-matrix adhesions, are comprised of clusters of integrin receptors associated with large complexes of signaling and structural proteins linked to the actin cytoskeleton (Burridge et al. 1996; Yamada et al. 1997). Focal adhesions were first identified by interference reflection microscopy, as areas of close association with the substratum (Curtis 1964; Izzard and Lochner 1976), and then subsequently characterized by electron microscopy as electron-dense plaques associated with actin filament bundles (Abercrombie et al. 1971; Heath and Dunn 1978). Focal adhesions are elongated in morphology and reside in both central and peripheral regions of the cell, and are generally found at the ends of actin filament bundles. Analogous adhesion structures have been observed in vivo in endothelial cells (Kano et al. 1996), skeletal muscle myotendinous junctions (Turner et al. 1991), and neuronal growth cones (Cypher and Letourneau 1991), and highly elongated adhesions have also been reported in vivo (Cukierman et al. 2001).

Focal adhesions serve both structural and signaling functions. The structural function is to connect actin stress fibers to the ECM by the association of integrins with linking proteins including talin, $\alpha$-actinin, and vinculin. This connection provides the traction forces observed in motile fibroblast-like cells, and thus alters cell migration. Talin depletion studies show its importance in transmitting force to the substratum as well as its critical role in adhesion formation and maturation (Zhang et al. 2008). Talin binds both integrin and actin, and it also binds to vinculin, which, in turn, binds to $\alpha$-actinin and actin, and therefore talin could link integrin and actin in multiple ways. Depletion of $\alpha$-actinin also inhibits adhesion maturation; but its role in force transmission has not been studied (Choi et al. 2008). $\alpha$-actinin depletion, however, has pleiotropic effects because of its role in bundling actin throughout the cell as well as its role in adhesion. Vinculin depletion does not produce the dramatic effects seen with talin and $\alpha$-actinin depletion and presumably is important for adhesion strength but not critical for adhesion formation (Xu et al. 1998).

More than 150 components have now been identified as adhesion-associated (Zamir and Geiger 2001; Hynes 2002; Wozniak 2004; Romer et al. 2006; Zaidel-Bar and Geiger 2010). They include integral membrane proteins (e.g., integrins, syndecans), proteins linked to actin (e.g., talin, vinculin, $\alpha$-actinin, zyxin), and signaling and adaptor proteins (e.g., the Src tyrosine kinase, focal adhesion kinase [FAK], paxillin, and the integrin-linked kinase [ILK]) (Turner 2000; Zamir and Geiger 2001; Frame 2004; Mitra et al. 2005; Legate et al. 2006). Focal adhesions also contain proteins that likely transiently associate with focal adhesions and regulate migration, e.g., p21-activated kinase (PAK), the Rho family of GTPases (Ridley et al. 1994), calcium-dependent protease calpain 2 (Beckerle et al. 1987), and the tyrosine phosphatase SHP-2 (Yu et al. 1998).

\section{Podosomes and Invadopodia}

Highly migratory and invasive cells form specialized types of integrin-mediated adhesions, referred to as a podosomes or invadopodia (Fig. 1). Podosomes were identified in fibroblasts transformed by the $\mathrm{v}$-Src oncogene (Tarone et al. 1985). They have also been observed in cells of monocytic lineage such as osteoclasts, macrophages and dendritic cells (Linder et al. 1999). The related protrusive structures, invadopodia, are generally found in invasive cancer cells. Both podosomes and invadopodia are actin-rich structures that have the capacity for matrix degradation. The relationship between podosomes and invadopodia is not clearly defined in the literature; however, the actin-rich protrusive structures seen in invasive cancer cells are referred to as invadopodia, and the ring structures that form in immune cells and osteoclasts are termed podosomes. Invadopodia 
are also seen in vivo and appear to be important for cancer cell invasion into blood vessels, an early step in the metastatic process (Yamaguchi and Condeelis 2007). Interestingly, breast cancer cells can form both invadopodia and focal adhesions in vitro, and they are differentially regulated by FAK/Src signaling (Chan et al. 2009).

Podosome and invadopodia architecture is defined by an actin-rich core, in which the actin polymerizing machinery and actin regulatory proteins function to drive membrane protrusion. In podosomes, but not invadopodia, this core is surrounded by a ring structure comprised of signaling and adaptor proteins including focal adhesion proteins such as talin and paxillin. In contrast to focal adhesions, podosomes and invadopodia are not associated with large actin filament bundles but are primary sites of rapid actin polymerization and contain actin regulatory proteins, including cortactin, gelsolin, WASP, Rho GTPases, and the actin nucleating Arp $2 / 3$ complex. $\beta 1, \beta 2$, and $\beta 3$ integrins localize to podosomes and invadopodia and are found within both the actin rich core and the surrounding ring structure. Src family kinases (Gavazzi et al. 1989) and Pyk2 (Bruzzaniti et al. 2005) also associate with the core.

Diseases that result in abnormal podosome formation highlight their essential role in normal immune responses in vivo. Macrophages and dendritic cells from patients with Wiskott-Aldrich Syndrome and WASP mutations lack podosomes, and have revealed a key role for WASP in podosome function (Linder et al. 1999). WASP plays a critical role in regulating podosome dynamics (Calle et al. 2008), matrix degradation (Dovas et al. 2009), and chemotaxis (Jones et al. 2002; Tsuboi 2006), contributing to disease pathogenesis in patients with Wiskott-Aldrich syndrome. Moreover, macrophages from patients with the autoinflammatory disease, pyogenic sterile arthritis, pyoderma gangrenosum, and acne (PAPA) syndrome, also show impaired podosome formation and decreased invasive migration (Cortesio et al. 2010). There is, therefore, substantial interest in understanding the mechanisms that regulate podosome formation and turnover and how these functions contribute to disease pathogenesis.

\section{Mechanisms of Adhesion Assembly}

The adhesions that form in protrusions are critical for cell migration. High traction forces reside at the cell front, as the cell pushes forward during protrusion and also pulls the central region of the cell and the rear forward. Furthermore, the Rho GTPases, on which signals that regulate actin organization and adhesion converge, are regulated by signaling components that reside in protrusions. The primary migration-related downstream effectors of the Rho GTPases are molecules that regulate actin polymerization, myosin II contraction, or microtubule dynamics and organization. It is no surprise, therefore, that actin polymerization, organization, and contraction drive adhesion formation and turnover.

Recent evidence suggests that nascent adhesions, precursors to focal adhesions, are formed within the lamellipodium of migrating cells. Their rate of formation is coupled to the rate of actin polymerization and inhibitors of actin polymerization impair the formation of nascent adhesions (Alexandrova et al. 2008; Choi et al. 2008). These small adhesions are likely smaller than the resolution of light microscopy and have a short lifetime of $\sim 1 \mathrm{~min}$. They have two fates: they can turn over at the rear of the lamellipodial array of dendritic actin or proceed to grow and elongate at the border of the lamellipodium and lamellum, where actin tends to be more bundled. Thus, their formation and life cycle appears to be intimately linked to actin polymerization and organization (Choi et al. 2008).

The mechanism by which the adhesions are nucleated is unclear. Abundant activated integrin in protrusions suggests a mechanism in which preactivated integrins bind to a multivalent or clustered ECM ligand (Kiosses et al. 2001), like fibronectin, and this induces a conformational change in the integrin and/or clustering of receptors that leads to the incorporation of other components. Because nascent 
adhesions form in the lamellipodium, which is rich in Arp2/3, the coupling with actin polymerization, and the observation that FAK and vinculin bind to Arp2/3, point to one of these interactions as a participant in adhesion nucleation as well. All components enter these adhesions at about the same time suggesting some kind of concerted, rather than highly regulated assembly mechanism. This is consistent with assembly by preformed complexes but does not show it directly or require it.

The origin of adhesion components has been studied for decades with little resolution. Two studies have visualized integrins undergoing directed movement in protrusions. One tracks them to the leading edge (Schmidt et al. 1993), and the other shows them associated with actin "comet tails" moving across the leading edge (Galbraith et al. 2007). Although there is evidence that integrins cycle from the rear (Lawson and Maxfield 1995), it is not clear that this is a general mechanism. Recent studies suggest a more localized cycling at least in fibroblasts or tumor cells (Caswell et al. 2009).

The boundary between the lamellum and the lamellipodium is a transition zone for actin organization and initial adhesion maturation (Choi et al. 2008). Adhesions that do not turn over and disassemble in this region elongate centripetally and grow in size. This elongation differs from nascent adhesion formation in many ways. It occurs along thin actin filament bundles that contain $\alpha$-actinin, which serves to organize the bundles and restrain adhesions to their termini. Unlike nascent adhesions, the addition of components during elongation is sequential. Paxillin, for example, enters early, whereas vinculin enters later. Finally, the maturation step also requires myosin II, in contrast to the formation of nascent adhesions.

The mechanism by which myosin II mediates maturation is an area of great interest and activity. Both the bundling and contractile activities of myosin II are required for maturation (Vicente-Manzanares et al. 2009). Myosin II mutants that bundle but do not contract, promote partial maturation. However, the contractile activity is required for maturation into large adhesions. On the one hand, the bundling would produce a clustering of integrins and other adhesion components linked to actin. The general notion is that contraction puts tension on adhesion molecules and induces changes in their conformation, thus opening new sites for binding or posttranslational modification (Sawada et al. 2006). Tension-sensitive molecules include Cas, talin, fibronectin, and integrin (Zhong et al. 1998; Sawada et al. 2006; del Rio et al. 2009; Friedland et al. 2009). Other molecules respond to tension by entering or leaving adhesions. Zyxin, for example, moves from adhesions to actin filaments under force (Yoshigi et al. 2005), and vinculin enters adhesions in response to force (Grashoff et al. 2010).

\section{Regulation of Adhesion Assembly}

Adhesion assembly is regulated by Rho GTPases, which in turn are regulated by adhesiongenerated signals. The migration-related effects of the Rho GTPases include actin polymerization, by promoting monomer formation (cofilin), nucleation/branching (Arp2/3) and elongation (formins), and actomyosin contraction. Rac and $\mathrm{Cdc} 42$ act as regulators of $\operatorname{Arp} 2 / 3$ through Wave/Scar/Wasp, and Wash (Campellone and Welsh 2010), which nucleate actin branches; whereas $\mathrm{Cdc} 42$ and Rho regulate formins, which lead to a processive elongation of actin (Campellone and Welsh 2010). Rho also regulates contractility by activating Rho kinase, which phosphorylates the regulatory light chain (RLC) of myosin II and inhibiting myosin phosphatase. This leads to increased myosin II-mediated contraction and bundling of actin. $\mathrm{Rac} / \mathrm{Cdc} 42$ may also regulate myosin activity through PAK by inhibiting MLCK or phosphorylating RLC directly (Vicente-Manzanares et al. 2009).

The Rho GTPases, in turn, are regulated by signaling networks in adhesions. These networks couple integrin signaling with that initiated by receptor tyrosine kinases, G-coupled protein receptors, and other receptor-initiated signaling pathways. The network of interactions is complex and involves a very large number of 
kinases and adapters. The role of signaling complexes is a major theme (Parsons et al. 2010). Paxillin and FAK are the two best understood in this regard. They contain binding domains that associate, either directly or indirectly, with one or more GEFs and GAPs that regulate the Rho GTPases (Brown and Turner 2004). In this regard, paxillin emerges as a "Rac hub." These associations, in turn, are regulated by receptor-mediated phosphorylation. Clearly, in polarized cells migrating directionally (Fig. 2), the activation of the Rho GTPases is polarized with Rac activity highest at the front and weak at the rear (Kraynov et al. 2000). This could occur by localized GEF/GAP or a polarized GEF/GAP distribution.

\section{Variations in Adhesion Formation}

The size, morphology, and distribution of adhesions seem to depend on the cell type and nature of the ECM. Some cells show many small adhesions near the leading edge and few large adhesions in the central and rear areas; whereas, others have large adhesions throughout the cell with few smaller adhesions. Although many factors likely contribute, the intrinsic contractility of the cell and pliability of the matrix likely contribute, at least in some situations. Because adhesion maturation is driven by myosin II contractility (Pelham and Wang 1997), the nature of the adhesions themselves and the pliability of the surrounding matrix could affect the tension sensed at the adhesion and thereby affect the rate and/or extent of maturation. Inhibiting myosin II, for example, leads to smaller adhesions (Pelham and Wang 1997; Vicente-Manzanares et al. 2007). Furthermore, cells migrating along collagen fibers, for example, show elongated adhesions because of the geometry and other properties of the collagen fibers. Finally, large focal adhesions are seldom seen in three dimensions (Cukierman et al. 2001; Kubow and Horwitz 2011). One explanation is that the dimensionality creates a different organization of the cellular actin filaments by virtue of the placement of adhesions and resulting intracellular force field that they produce. Another explanation could lie in the differences in pliability of 3-D matrices that are not tethered to rigid substrata, which is the case in 2-D. Plating cells on top of gels of varying pliability leads to altered adhesion sizes (Pelham and Wang 1997).

\section{Adhesion Disassembly and Turnover During Cell Migration}

Polarized cell migration is characterized by asymmetric adhesion dynamics with formation of nascent adhesions at the leading edge that turn over rapidly and the disassembly of integrin-mediated adhesions at the rear mediating rear-end detachment (Fig. 2) (reviewed in Webb et al. 2002; Broussard et al. 2008; Parsons et al. 2010). As discussed above, near the leading edge, nascent adhesions are formed that mediate traction forces; these adhesions can either mature to form larger, stable adhesions, or they can turn over as new adhesions and protrusions form at the leading edge. In contrast, at the rear of the cell, disassembly of adhesions is associated with rear-end retraction and detachment allowing for cell-body translocation.

\section{Turnover of Adhesions in Protrusions}

Nascent adhesions at the leading edge either mature into stabilized adhesions or turn over. Paxillin-containing adhesions near the leading edge are highly dynamic and rapidly form and turn over (Webb et al. 2004; Choi et al. 2008). These adhesions turn over at the rear of the lamellipodium-the Arp2/3-rich region of active actin polymerization near the leading edge. The turnover appears to be coupled to actin organization in this region, because it is where actin is severed and reorganized and independent of myosin II contractility.

Instead of undergoing rapid turnover, some of the nascent adhesions grow, elongate, and show a differential increase in certain adhesion components like vinculin and $\alpha$-actinin. This occurs when the protrusion pauses in response to myosin II activity. The mechanisms that regulate the decision to disassemble or to elongate and grow are not understood. However, these mechanisms are likely the regulators 
of the directed migration of mesenchymal cells and may also contribute to directional decision-making during pseudopod selection by amoeboid cells migrating in vitro (Andrew and Insall 2007) and in vivo (Cvejic et al. 2008; Yoo et al. 2010).

The turnover of focal adhesions in protrusions is regulated by focal adhesion kinase (FAK) and Src tyrosine kinases. Fibroblasts or cancer cells deficient in FAK have reduced migration and form increased numbers of large peripheral adhesions that have impaired turnover (Ilic et al. 1995; Sieg et al. 2000; Hsia et al. 2003; Webb et al. 2004; Chan et al. 2009). The FAK autophosphorylation site and its kinase activity are both important for FAK-induced adhesion turnover and cell migration. Fibroblasts from mice lacking the Src kinases, c-Src, Fyn, and Yes, or ectopically expressing kinase-dead c-Src also show impaired migration and large peripheral adhesions with reduced turnover (Fincham and Frame 1998; Klinghoffer et al. 1999; Webb et al. 2004). On the other hand, infection of cells with Rous sarcoma virus and activation of Src induces disassembly of focal adhesions. These studies support a critical role for FAK/Src signaling in adhesion turnover. Although many mechanisms likely contribute, these kinases phosphorylate Rho GTPase signaling scaffolds like paxillin, which in turn bind GEFs for Rac (Brown and Turner 2004; Zaidel-Bar et al. 2007), regulate myosin activity, and actin polymerization. Thus, both tyrosine kinases and phosphatases play a role (Yu et al. 1998; Angers-Lousteau et al. 1999; Sastry et al. 2002); it follows therefore that dynamic cycles of phosphorylation-dephosphorylation at adhesion sites are likely essential for adhesion turnover and migration. In this regard, cells deficient in the protein tyrosine phosphatase (PTP)-PEST show an increase in focal adhesion size and reduced migration rates (Angers-Lousteau et al. 1999; Sastry et al. 2002). Moreover, SHP-2-deficient fibroblasts display phenotypes similar to the FAK-knockout cells with large peripheral adhesions and impaired migration (Yu et al. 1998). It is likely that kinases and phosphatases exert their effects on adhesion turnover by targeting specific adaptor proteins. For example, p130Cas is hyperphosphorylated in (PTP)-PEST-deficient cells and $\mathrm{Cas}^{-/}$fibroblasts show defects in adhesions, spreading, and migration (Honda et al. 1998), suggesting that Cas functions downstream from PTP-PEST in adhesion dynamics. In addition, application of tensile force to p130Cas changes its conformation making it more susceptible to Src kinase phosphorylation providing a link between tension, regulated phosphorylation, and the modulation of adhesion dynamics (Geiger 2006; Sawada et al. 2006). Other downstream targets of FAK/Src signaling include paxillin, a key regulator of adhesion dynamics that associates with downstream effectors including PKL, GIT1, PIX, and PAK as well as Cas/Crk (Ballestrem et al. 2006) to regulate adhesion dynamics (Brown et al. 2005).

FAK/Src signaling lies upstream of the Rho family GTPases, which regulate adhesion and actin organization. For example, $\mathrm{FAK}^{-/-}$ fibroblasts have constitutive activation of Rho that stabilizes adhesions (Ilic et al. 1995). Conversely, FAK/Src signaling activates p190RhoGAP, which decreases Rho activity and recruits a complex including Rac and PAK that induces adhesion turnover (Schober et al. 2007). FAK thereby induces a switch from Rho activation to the activation of Rac that targets downstream effectors including PAK. PAK may affect adhesion turnover by modulating the activity of myosin light-chain kinase (MLCK) and LIM kinase. FAK therefore orchestrates adhesion turnover in part by switching from Rhomediated adhesion maturation to Rac-induced adhesion turnover. Reduced myosin II activity leads to the loss of large adhesions and rapid protrusion (Vicente-Manzanares et al. 2009).

Microtubules target to adhesion sites and mediate the turnover of focal adhesions (Kaverina 1999) potentially through the modulation of Rho GTPase signaling (Broussard et al. 2008). Microtubule-induced disassembly of adhesion sites can also occur through a FAK/ dynamin pathway independently of Rho and Rac activation (Ezratty et al. 2005). This microtubule-induced disassembly is characterized by integrin endocytosis at adhesion sites regulated 
by clathrin and specific clathrin adaptor proteins (Ezratty et al. 2009); however, this pathway appears to be active on adhesions that reside in central regions of the cell. A recent report suggests that type I phosphatidylinositol kinase $\beta$ (PIPKIß), which generates phosphatidylinositol-4,5-bisphosphate $\left(\mathrm{PI} 4,5 \mathrm{P}_{2}\right)$ can also regulate internalization of active $\beta 1$ integrins and focal adhesion turnover in motile cells (Chao et al. 2010). Taken together, these studies support a key role for microtubule-mediated integrin internalization in the turnover of some focal adhesions.

Disassembly and Retraction of the Cell's Rear

The regulation of adhesion disassembly at the trailing edge of cells is less well understood than adhesion turnover at the leading edge. Adhesive release at the cell rear can involve weakening or severing of the integrin-ECM or integrin-cytoskeletal linkages and is driven, at least in part, through contractile forces. As a result, integrins can separate from the actin cytoskeleton and remain associated with the substratum as integrin "footprints," while the cytoskeleton-associated components translocate toward the cell body and disperse as the adhesion disassembles (Regen and Horwitz 1992; Smilenov et al. 1999). It is also likely that integrin endocytosis and recycling contributes to adhesion release for neutrophils migrating on $\alpha v \beta 3$ integrin ligands (Lawson and Maxfield 1995), although it appears that this does not contribute in all cell types (Caswell et al. 2009). Inhibition of the $\mathrm{Ca}^{++} /$calmodulin-activated protein phosphatase $2 \mathrm{~B}$, calcineurin, impairs integrin recycling, neutrophil rear-end detachment, and directed migration (Lawson and Maxfield 1995).

Rho/ROCK signaling mediates retraction of the trailing edge of cells and has been implicated in adhesion disassembly during cell detachment (Webb et al. 2004). Inhibition of Rho kinase or MLCK induces an elongated morphology with impaired rear-end detachment (Worthylake et al. 2001). Activation of PAK has also been implicated in retraction of the trailing edge of cells by affecting cell contraction (Chung and Firtel 1999; Kiosses et al. 1999). Contractile forces at the cell's rear are likely key regulators of adhesive release by weakening integrin-substrate or integrin-cytoskeletal interactions; however, in monocytes, changes in avidity appear important as well (Worthylake et al. 2001). Other modifications such as change in phosphorylation or proteolysis can contribute to the severing of linkages at the cell's rear.

The intracellular calcium-dependent proteases calpains are also important for the adhesion disassembly in migrating fibroblasts (Huttenlocher et al. 1997; Dourdin et al. 2001) and have been implicated in the destabilization of focal adhesions downstream from microtubules (Bhatt et al. 2002). Calpains cleave several proteins found in focal adhesions including FAK, paxillin, and talin (Carragher et al. 1999; Glading et al. 2002; Franco et al. 2004, 2005), and these proteolytic events mediate adhesion disassembly. Specifically, calpain-mediated proteolysis of talin and FAK can be rate-limiting steps in focal adhesion turnover (Franco et al. 2004; Chan et al. 2010). Calpains have also been implicated in the disassembly of podosomes in dendritic cells (Calle et al. 2006) and invadopodia in cancer cells (Cortesio et al. 2008), suggesting that calpains regulate the dynamics of diverse types of adhesions.

In addition to regulating adhesion turnover at the leading edge, FAK, Src, Shp2, and other regulators of phosphorylation likely play a key role in adhesion disassembly at the rear. For example, FAK-Src signaling may mediate adhesion disassembly through the regulation of myosin-light chain kinase (MLCK) and ERK (Webb et al. 2004). FAK may also regulate adhesion disassembly through its association with calpain and ERK at focal adhesions (Carragher et al. 2003).

Substantial evidence implicates a critical role for the cellular contractile machinery in uropod de-adhesion and retraction during amoeboid cell motility in addition to focal adhesion disassembly and detachment of the trailing edge of fibroblast-like cells (reviewed in SanchezMadrid and Serrador 2009). Fibroblasts deficient in myosin IIA show impaired adhesion 
disassembly and rear detachment (VicenteManzanares et al. 2007). In amoeboid cells RhoA-induced activation of ROCK mediates myosin light chain phosphorylation at the uropod resulting in the activation of myosin II (Eddy et al. 2000; Xu et al. 2003). Moreover, down-regulation of myosin heavy chain IIa using small interfering RNA (siRNA) inhibits uropod formation and motility of T cells (Jacobelli et al. 2004). Although regulated uropod detachment is likely important for leukocyte motility, the precise function of the uropod in regulating leukocyte motility remains unknown. It is possible that the uropod enables cells to migrate through constricted interstitial tissues in 3-D in addition to affecting rear detachment (reviewed in Sanchez-Madrid and Serrador 2009). It has recently been proposed that the rear of fibroblasts may provide the driving force for breaking cell symmetry during fibroblast locomotion (Vicente-Manzanares et al. 2008). This raises the intriguing possibility that the trailing edge of the cell may drive cell migration by forming a defined rear prior to the formation of polarized cell protrusion (Vicente-Manzanares et al. 2008 and reviewed in Cramer 2010). There is, therefore, much more to be learned about how adhesion regulation at the cell's rear drives the directed migration of both fibroblast and amoeboid cells (Sanchez-Madrid and Serrador 2009; Cramer 2010).

\section{SUMMARY}

Significant progress has been made in understanding the molecular mechanisms that regulate the adhesion dynamics and signaling that mediate cell migration. Many of the mechanisms that govern adhesion formation and disassembly also play roles in the regulation of podosome dynamics, despite their large structural differences. For example, Src kinases are important both for the turnover of focal adhesions and podosomes. However, Src kinase activity is necessary for podosome formation and expression of the constitutively active vSrc kinase in cells that normally form focal adhesions promotes a switch to the formation of podosomes. It is likely that differences in the regulation of Src signaling determine focal adhesion and podosome formation. A key question for future investigation concerns the molecular determinants that promote this switch between the formation of focal adhesions and the generation of invasive, matrix-degrading adhesion structures. It will also be important to characterize the adhesions that reside in cells migrating in 3-D, and how the microenvironment influences cell signaling, and the temporal and spatial dynamics of adhesions and the signals they produce during different modes of migration through 3-D tissues in vivo.

\section{ACKNOWLEDGMENTS}

The writing of this review was supported by NIH grants CA085862-08 to A.H. and GM23244 and the Cell Migration Consortium grant U54-GM064346 to A.R.H. We also thank Christa Cortesio and Miguel Vicente-Manzanares for Figures 1 and 2, respectively.

\section{REFERENCES}

Abercrombie M, Heaysman JE, Pegrum SM. 1971. The locomotion of fibroblasts in culture. IV. Electron microscopy of the leading lamella. Exp Cell Res 67: 359-367.

Abram CL, Lowell CA. 2009. The ins and outs of leukocyte integrin signaling. Annu Rev Immunol 27: 339-362.

Alexandrova AY, Arnold K, Schaub S, Vasiliev JM, Meister JJ, Bershadsky AD, Verkhovsky AB. 2008. Comparative dynamics of retrograde actin flow and focal adhesions: Formation of nascent adhesions triggers transition from fast to slow flow. PLoS One 3: 3234.

Andrew N, Insall RH. 2007. Chemotaxis in shallow gradients is mediated independently of PtdIns 3-kinase by biased choices between random protrusions. Nat Cell Biol 9: 193-200.

Angers-Loustau A, Cote JF, Charest A, Dowbenko D, Spencer S, Lasky LA, Tremblay ML. 1999. Protein tyrosine phosphatase-PEST regulates focal adhesion disassembly, migration, and cytokinesis in fibroblasts. J Cell Biol 144: 1019-1031.

Ballestrem C, Erez N, Kirchner J, Kam Z, Bershadsky A, Geiger B. 2006. Molecular mapping of tyrosine-phosphorylated proteins in focal adhesions using fluorescence resonance energy transfer. J Cell Sci 119: 866-875.

Beckerle MC, Burridge K, DeMartino GN, Croall DE. 1987. Colocalization of calcium-dependent protease II and one of its substrates at sites of cell adhesion. Cell 51: 569-577.

Bhatt A, Kaverina I, Otey C, Huttenlocher A. 2002. Regulation of focal complex composition and disassembly by the calcium-dependent protease calpain. J Cell Sci 115: 3415-3425. 
Integrins in Cell Migration

Brabek J, Constancio SS, Siesser PF, Shin NY, Pozzi A, Hanks SK. 2005. Crk associated substrate tyrosine phosphorylation sites are critical for invasion and metastasis of Src-transformed cells. Mol Cancer Res 3: 307-315.

Broussard JA, Webb DJ, Kaverina I. 2008. Asymmetric focal adhesion disassembly in motile cells. Curr Opin Cell Biol 20: 85-90.

Brown MC, Turner CE. 2004. Paxillin: Adapting to change. Physiol Rev 84: 1315-1339.

Brown MC, Cary LA, Jamieson JS, Cooper JA, Turner CE. 2005. Src and FAK kinases cooperate to phosphorylate paxillin kinase linker, stimulate its focal adhesion localization and regulate cell spreading and protrusiveness. Mol Biol Cell 16: 4316-4328.

Brown CM, Hebert B, Kolin DL, Zareno J, Whitmore L, Horwitz AR, Wiseman PW. 2006. Probing the integrinactin linkage using high-resolution protein velocity mapping. J Cell Sci 119: 5204-5214.

Bruzzaniti A, Neff L, Sanjay A, Horne WC, De Camilli P, Baron R. 2005. Dynamin forms a Src kinase-sensitive complex with $\mathrm{Cbl}$ and regulates podosomes and osteoclast activity. Mol Biol Cell 16: 3301-3313.

Buccione R, Orth JD, McNiven MA. 2004. Foot and mouth: Podosomes, invadopodia and circular dorsal ruffles. Nat Rev Mol Cell Biol 5: 647-657.

Burridge K, Chrzanowska-Wodnicka M. 1996. Focal adhesions, contractility, and signaling. Annu Rev Cell Dev Biol 12: 463-518.

Calle Y, Carragher NO, Thrasher AJ, Jones GE. 2006. Inhibition of calpain stabilises podosomes and impairs dendritic cell motility. J Cell Sci 119: 2375-2385.

Calle Y, Antón I, Thrasher A, Jones G. 2008. WASP and WIP regulate podosomes in migrating leukocytes. J Microsc 231: 494-505.

Campellone KG, Welch MD. 2010. A nucleator arms race: Cellular control of actin assembly. Nat Rev Mol Cell Biol 11: $237-251$.

Carragher NO, Levkau B, Ross R, Raines EW. 1999 Degraded collagen fragments promote rapid disassembly of smooth muscle focal adhesions that correlates with cleavage of pp125(FAK), paxillin, and talin. J Cell Biol 147: 619-630.

Carragher NO, Westhoff MA, Fincham VJ, Schaller MD, Frame MC. 2003. A novel role for FAK as a proteasetargeting adaptor protein: Regulation by pp42 ERK and Src. Curr Biol 13: 1442-1450.

Caswell PT, Vadrevu S, Norman JC. 2009. Integrins: Masters and slaves of endocytic transport. Nat Rev Mol Cell Biol 10: $843-853$.

Chan BMC, Matsuura N, Takada Y, Zetter BR, Hemler ME. 1990. In vitro and in vivo consequences of VLA-1 expression on rhabdomyosarcoma cells. Science 251: 16001602.

Chan KT, Cortesio CL, Huttenlocher A. 2009. FAK alters invadopodia and focal adhesion composition and dynamics to regulate breast cancer invasion. J Cell Biol 185: $357-370$.

Chan KT, Bennin DA, Huttenlocher A. 2010. Regulation of focal adhesion dynamics by calpain-mediated proteolysis of FAK. J Biol Chem 285: 418-426.
Chao WT, Ashcroft F, Daquinag AC, Vadakkan T, Wei Z, Zhang P, Dickinson ME, Kunz J. 2010. Type I phosphatidylinositol phosphate kinase $\beta$ regulates focal adhesion disassembly by promoting $\beta 1$ integrin endocytosis. Mol Cell Biol 30: 4463-4479.

Choi CK, Vicente-Manzanares M, Zareno J, Whitmore LA, Mogilner A, Horwitz AR. 2008. Actin and $\alpha$-actinin orchestrate the assembly and maturation of nascent adhesions in a myosin II motor-independent manner. Nat Cell Biol 10: 1039-1050.

Chung CY, Firtel RA. 1999. PAKa, a putative PAK family member is required for cytokinesis and the regulation of the cytoskeleto in Dictyostelium discoideum cells during chemotaxis. J Cell Biol 147: 559-576.

Cortesio CL, Chan KT, Perrin BJ, Burton NO, Zhang S, Zhang ZY, Huttenlocher A. 2008. Calpain 2 and PTP1B function in a novel pathway with Src to regulate invadopodia dynamics and breast cancer cell invasion. J Cell Biol 180: 957-971.

Cortesio CL, Cooper KM, Wernimont SA, Kastner DL, Huttenlocher A. 2010. Impaired podosome formation and invasive migration of macrophages from patients with PAPA syndrome and a PSTPIP1 mutation. Arthritis Rheum 62: 2556-2558.

Cramer LP. 2010. Forming the cell rear first: Breaking cell symmetry to trigger directed cell migration. Nat Cell Biol 12: 628-632.

Cukierman E, Pankov R, Stevens DR, Yamada KM. 2001. Taking cell-matrix adhesions to the third dimension. Science 294: 1708-1712.

Curtis AS. 1964. The mechanism of adhesion of cells to glass: A study by interference reflection microscopy. J Cell Biol 20: 199-215.

Cvejic A, Hall C, Bak-Maier M, Flores MV, Crosier P, Redd MJ, Martin P. 2008. Analysis of WASp function during wound inflammatory response-live imaging studies in zebrafish larvae. J Cell Sci 121: 3196-3206.

Cypher C, Letourneau PC. 1991. Identification of cytoskeletal, focal adhesion, and cell adhesion proteins in growth cone particles isolated from developing chick brain. J Neurosci Res 30: 259-265.

del Rio A, Perez-Jimenez R, Liu R, Roca-Cusachs P, Fernandez JM, Sheetz MP. 2009. Stretching single talin rod molecules activates vinculin binding. Science 323: 638-641.

DiMilla PA, Stone JA, Quinn JA, Albelda SM, Lauffenburger DA. 1993. Maximal migration of human smooth muscle cells on fibronectin and type IV collagen occurs at an intermediate attachment strength. J Cell Biol 122: 729737.

Dourdin N, Bhatt AK, Dutt P, Greer PA, Arthur JS, Elce JS, Huttenlocher A. 2001. Reduced cell migration and disruption of the actin cytoskeleton in calpain-deficient embryonic fibroblasts. J Biol Chem 276: 48382-48388.

Dovas A, Gevrey J, Grossi A, Park H, Abou-Kheir W, Cox D. 2009. Regulation of podosome dynamics by WASp phosphorylation: Implication in matrix degradation and chemotaxis in macrophages. J Cell Sci 122: 3873-3882.

Doyle AD, Wang FW, Matsumoto K, Yamada KM. 2009. One-dimensional topography underlies three-dimensional fibrillar cell migration. J Cell Biol 184: 481-490. 
Eddy RJ, Pierini LM, Matsumura F, Maxfield FR. 2000 Calcium-dependent myosin II activation is required for uropod retraction during neutrophil migration. $J$ Cell Sci 113: 1287-1298.

Ezratty EJ, Partridge MA, Gundersen GG. 2005. Microtubule-induced focal adhesion disassembly is mediated by dynamin and focal adhesion kinase. Nat Cell Biol 7: 581-590.

Ezratty EJ, Bertaux C, Marcantonio EE, Gundersen GG 2009. Clathrin mediates integrin endocytosis for foca adhesion disassembly in migrating cells. J Cell Biol 187: 733-747.

Fincham VJ, Frame MC. 1998. The catalytic activity of Src is dispensable for translocation to focal adhesions but controls the turnover of these structures during cell motility. EMBO J 17: 81-92.

Frame MC. 2004. Newest findings on the oldest oncogene; how activated src does it. J Cell Sci 117: 989-998.

Franco SJ, Huttenlocher A. 2005. Regulating cell migration: Calpains make the cut. J Cell Sci 118: 829-838.

Franco SJ, Rodgers MA, Perrin BJ, Han J, Bennin DA, Critchley DR, Huttenlocher A. 2004. Calpain-mediated proteolysis of talin regulated adhesion dynamics. Nat Cell Biol 6: 977-983.

Friedl P, Wolf K. 2010. Plasticity of cell migration: A multiscale tuning model. J Cell Biol 188: 11-19.

Friedland JC, Lee MH, Boettiger D. 2009. Mechanically activated integrin switch controls $\alpha 5 \beta 1$ function. Science 323: $642-644$.

Fuortes M, Jin WW, Nathan C. 1994. $\beta 2$ integrin-dependent tyrosine phosphorylation of paxillin in human neutrophils treated with tumor necrosis factor. J Cell Biol 127: 1477-1483.

Galbraith CG, Yamada KM, Galbraith JA. 2007. Polymerizing actin fibers position integrins primed to probe for adhesion sites. Science 315: 992-995.

Gavazzi I, Nermut MV, Marchisio PC. 1989. Ultrastructure and gold-immunolabelling of cell-substratum adhesions (podosomes) in RSV-transformed BHK cells. J Cell Sci 94: 85-99.

Geiger B. 2006. A role for p130Cas in mechanotransduction Cell 127: 879-881.

Geiger B, Yamada KM. 2011. Molecular architecture and function of matrix adhesions. Cold Spring Harb Perspect Biol doi: 10.1101/cshperspect.a005033.

Geiger B, Spatz JP, Bershadsky AD. 2009. Environmental sensing through focal adhesions. Nat Rev Mol Cell Biol 10: $21-33$.

Giannone G, Dubin-Thaler BJ, Rossier O, Cai Y, Chaga O, Jiang G, Beaver W, Döbereiner HG, Freund Y, Borisy G, et al. 2007. Lamellipodial actin mechanically links myosin activity with adhesion-site formation. Cell 128: $561-575$.

Glading A, Lauffenburger D, Wells A. 2002. Cutting to the chase: Calpain proteases in cell motility. Trends Cell Biol 12: $46-54$.

Grashoff C, Hoffman BD, Brenner MD, Zhou R, Parsons M, Yang MT, McLean MA, Sligar SG, Chen CS, Ha T, et al. 2010. Measuring mechanical tension across vinculin reveals regulation of focal adhesion dynamics. Nature 466: $263-266$.
Guo WH, Wang YL. 2007. Retrograde fluxes of focal adhesion proteins in response to cell migration and mechanical signals. Mol Biol Cell 18: 4519-4527.

Gupton SL, Waterman-Storer CM. 2006. Spatiotemporal feedback between actomyosin and focal-adhesion systems optimizes rapid cell migration. Cell 125: 13611374.

Han J, Lim CJ, Watanabe N, Soriani A, Ratnikov B, Calderwood DA, Puzon-McLaughlin W, Lafuente EM, Boussiotis VA, Shattil SJ, et al. 2006. Reconstructing and deconstructing agonist-inducded activation of integrin $\alpha$ IIbß3. Curr Biol 16: 1796-1806.

Heath JP, Dunn GA. 1978. Cell to substratum contacts of chick fibroblasts and their relation to the microfilament system. A correlated interference-reflexion and highvoltage electron-microscope study. J Cell Sci 29: 197-212.

Hodgson L, Pertz O, Hahn KM. 2008. Design and optimization of genetically encoded fluorescent biosensors: GTPase biosensors. Method Cell Biol 85: 63-81.

Honda H, Oda H, Nakamoto T, Honda Z, Sakai R, Suzuki T, Saito T, Nakamura T, Nakao K, Ishikawa T, et al. 1998. Cardiovascular anomaly, impaired actin bundling and resistance to Src-induced transformation in mice lacking p130Cas. Nat Genet 19: 361-365.

Hsia DA, Mitra SK, Hauck CR, Streblow DN, Nelson JA, Ilic D, Huang S, Li E, Nemerow GR, Leng J, et al. 2003. Differential regulation of cell motility and invasion by FAK. J Cell Biol 160: 753-767.

Hu K, Ji L, Applegate KT, Danuser G, Waterman-Storer CM. 2007. Differential transmission of actin motion within focal adhesions. Science 315: 111-115.

Huttenlocher A, Sandborg RS, Horwitz AF. 1995. Adhesion in cell migration. Curr Opin Cell Biol 7: 697-706.

Huttenlocher A, Ginsberg M, Horwitz A. 1996. Modulation of cell migration by integrin affinity and cytoskeletal interactions. J Cell Biol 134: 1551-1562.

Huttenlocher A, Palecek S, Lu Q, Zhang W, Mellgren R, Lauffenburger DA, Ginsberg M, Horwitz AF. 1997. Regulation of cell migration by the calcium-dependent protease calpain. J Biol Chem 272: 32719-32722.

Huveneers S, Danen EH. 2009. Adhesion signaling-crosstalk between integrins, Src and Rho. J Cell Sci 122: 10591069.

Hynes RO. 2002. Integrins: Bidirectional, allosteric signaling machines. Cell 110: 673-687.

Ilic D, Furuta Y, Kanazawa S, Takeda N, Sobue K, Nakatsuji N, Nomura S, Fujimoto J, Okada M, Yamamoto T. 1995. Reduced cell motility and enhanced focal adhesion contact formation in cells from FAK-deficient mice. Nature 377: $539-544$.

Izzard CS, Lochner LR. 1976. Cell-to-substrate contacts in living fibroblasts: An interference reflexion study with an evaluation of the technique. J Cell Sci 21: 129-159.

Jacobelli J, Chmura SA, Buxton DB, Davis MM, Krummel MF. 2004. A single class II myosin regulates T cell motility and stopping, but not synapse formation. Nat Immunol 5: $531-538$.

Jones G, Zicha D, Dunn G, Blundell M, Thrasher A. 2002. Restoration of podosomes and chemotaxis in WiskottAldrich syndrome macrophages following induced expression of WASp. Int J Biochem Cell Biol 34: 806-815. 
Kano Y, Katoh K, Masuda M, Fujiwara K. 1996. Macromolecular composition of stress fiber-plasma membrane attachment sites in endothelial cells in situ. Circ Res 79: 1000-1006.

Kaverina I, Krylyshkina O, Small JV. 1999. Microtubule targeting of substrate contacts promotes their relaxation and dissociation. J Cell Biol 146: 1033-1044.

Kiosses WB, Shattil SJ, Pampori N, Schwartz MA. 2001. Rac recruits high affinity integrin $\alpha v \beta 3$ to lamellipodia in endothelial cell migration. Nat Cell Biol 3: 316-320.

Klinghoffer RA, Sachsenmaier C, Cooper JA, Soriano P. 1999. Src family kinases are required for integrin but not PDGFR signal transduction. EMBO J 18: 2459-2471.

Kölsch V, Charest PG, Firtel RA. 2008. The regulation of cell motility and chemotaxis by phospholipid signaling. J Cell Sci 121: 551-559.

Kraynov VS, Chamberlain C, Bokoch GM, Schwartz MA, Slabaugh S, Hahn KM. 2000. Localized Rac activation dynamics visualized in living cells. Science 290: 333-337.

Kubow KE, Horwitz AR. 2011. Reducing background fluorescence reveals adhesions in 3D matrices. Nat Cell Biol 13: 3-5.

Lämmermann T, Sixt M. 2009. Mechanical modes of amoeboid cell migration. Curr Opin Cell Biol 21: 636-644.

Lämmermann T, Bader BL, Monkley SJ, Worbs T, WedlichSöldner R, Hirsch K, Keller M, Förster R, Critchley DR, Fässler R, et al. 2008. Rapid leukocyte migration by integrin-independent flowing and squeezing. Nature 453: $51-55$.

Lauffenburger DA, Horwitz AF. 1996. Cell migration: A physically integrated molecular process. Cell 84: 359369.

Lawson MA, Maxfield FR. 1995. $\mathrm{Ca}^{2+}$ and calcineurindependent recycling of an integrin to the front of migrating neutrophils. Nature 377: 75-79.

Lazarides E, Burridge K. 1975. $\alpha$-actinin: Immunofluorescent localization of a muscle structural protein in nonmuscle cells. Cell 6: 289-298.

Legate KR, Montanez E, Kudlacek O, Fassler R. 2006. ILK, PINCH and parvin: The tIPP of integrin signalling. Nat Rev Mol Cell Biol 7: 20-31.

Lim CJ, Kain KH, Tkachenko E, Goldfinger LE, Gutierrez E, Allen MD, Groisman A, Zhang J, Ginsberg MH. 2008. Integrin-mediated protein kinase A activation at the leading edge of migrating cells. Mol Biol Cell 19: 4930-4941.

Linder S. 2007. The matrix corroded: Podosomes and invadopodia in extracellular matrix degradation. Trends Cell Biol 17: 107-117.

Linder S, Aepfelbacher M. 2003. Podosomes: Adhesion hot-spots of invasive cells. Trends Cell Biol 13: 376-385.

Linder S, Nelson D, Weiss M, Aepfelbacher M. 1999. Wiskott-Aldrich syndrome protein regulates podosomes in primary human macrophages. Proc Natl Acad Sci 96: 9648-9653.

Lokuta M, Huttenlocher A. 2005. TNFa promotes a stop signal that inhibits neutrophil polarization and migration via a p38 MAPK pathway. J Leukocyte Biol 78: 210-219.

Mitchison TJ, Cramer LP. 1996. Actin-based cell motility and cell locomotion. Cell 84: 371-379.
Mitra SK, Hanson DA, Schlaepfer DD. 2005. Focal adhesion kinase: In command and control of cell motility. Nat Rev Mol Cell Biol 6: 56-68.

Moser M, Nieswandt B, Ussar S, Pozgajova M, Fässler R. 2008. Kindlin-3 is essential for integrin activation and platelet aggregation. Nat Med 14: 325-330.

Palecek SP, Loftus JC, Ginsberg MH, Lauffenburger DA, Horwitz AF. 1997. Integrin ligand binding properties govern cell migration speed through cell-substratum adhesiveness. Nature 385: 537-540.

Parsons JT, Horwitz AR, Schwartz MA. 2010. Cell adhesion: Integrating cytoskeletal dynamics and cellular tension. Nat Rev Mol Cell Biol 11: 633-643.

Pelham RJ, Wang YL. 1997. Cell locomotion and focal adhesions are regulated by substrate flexibility. Proc Natl Acad Sci 94: 13661-13665.

Regen CM, Horwitz AF. 1992. Dynamics of b1 integrin mediated adhesive contacts in motile fibroblasts. J Cell Biol 119: 1347-1359.

Ridley AJ. 1994. Membrane ruffling and signal transduction. Bioessays 16: 321-327.

Ridley AJ, Hall A. 1992. The small GTP-binding protein rho regulates the assembly of focal adhesions and actin stress fibers in response to growth factors. Cell 70: 389-399.

Ridley AJ, Schwartz MA, Burridge K, Firtel RA, Ginsberg MH, Borisy G, Parsons JT, Horwitz AR. 2003. Cell migration: Integrating signals from front to back. Science 302: 1704-1709.

Romer LH, Birukov KG, Garcia JG. 2006. Focal adhesions: Paradigm for a signaling nexus. Circ Res 98: 606-616.

Rottner K, Hall A, Small JV. 1999. Interplay between Rac and Rho in the control of substrate contact dynamics. Curr Biol 17: 640-648.

Sánchez-Madrid F, Serrador JM. 2009. Bringing up the rear: Defining the roles of the uropod. Nat Rev Mol Cell Biol 10: 353-359.

Sastry SK, Lyons PD, Schaller MD, Burridge K. 2002. PTP-PEST controls motility through regulation of Rac1. J Cell Sci 115: 4305-4316.

Sawada Y, Tamada M, Dubin-Thaler BJ, Cherniavskaya O, Sakai R, Tanaka S, Sheetz MP. 2006. Force sensing by mechanical extension of the Src family kinase substrate p130Cas. Cell 127: 1015-1026.

Schmidt CE, Horwitz AF, Lauffenburger DA, Sheetz MP. 1993. Integrin-cytoskeletal interactions in migrating fibroblasts are dynamic, asymmetric, and regulated. J Cell Biol 123: 977-991.

Schober M, Raghavan S, Nikolova M, Polak L, Pasolli HA, Beggs HE, Reichardt LF, Fuchs E. 2007. Focal adhesion kinase modulates tension signaling to control actin and focal adhesion dynamics. J Cell Biol 176: 667-680.

Seftor REB, Seftor EA, Gehlsen KR, Stetler-Steveson WG, Brown PD, Ruoslahti E, Hendrix MJC. 1992. Role of avb3 integrin in human melanoma cell invasion. Proc Natl Acad Sci 89: 1557-1561.

Shattil SJ, Kim C, Ginsberg MH. 2010. The final steps of integrin activation: The end game. Nat Rev Mol Cell Biol 11: 288-300.

Sieg DJ, Hauck CR, Ilic D, Klingbeil CK, Schaefer E, Damsky $\mathrm{CH}$, Schlaepfer DD. 2000. FAK integrates growth-factor 
and integrin signals to promote cell migration. Nat Cell Biol 2: 249-256.

Smilenov LB, Mikhailov A, Pelham RJ, Marcantonio EE Gundersen GG. 1999. Focal adhesion motility revealed in stationary fibroblasts. Science 286: 1172-1174.

Swaney KF, Huang CH, Devreotes PN. 2010. Eukaryotic chemotaxis: A network of signaling pathways controls motility, directional sensing, and polarity. Annu Rev Biophys 39: 265-289.

Tarone G, Cirillo D, Giancotti FG, Comoglio PM, Marchisio PC. 1985. Rous sarcoma virus-transformed fibroblasts adhere primarily at discrete protrusions of the ventral membrane called podosomes. Exp Cell Res 159: 141-157.

Truong H, Danen EH. 2009. Integrin switching modulates adhesion dynamics and cell migration. Cell Adh Migr 3: 179-181.

Tsuboi S. 2006. A complex of Wiskott-Aldrich syndrome protein with mammalian verprolins plays an important role in monocyte chemotaxis. J Immunol 176: 65766585.

Turner CE. 2000. Paxillin and focal adhesion signaling. Nat Cell Biol 2: E231-E236.

Turner CE, Kramarcy N, Sealock R, Burridge K. 1991. Localization of paxillin, a focal adhesion protein, to smooth muscle dense plaques, and the myotendinous and neuromuscular junctions of skeletal muscle. Exp Cell Res 192: 651-655.

Vicente-Manzanares M, Zareno J, Whitmore L, Choi CK, Horwitz AF. 2007. Regulation of protrusion, adhesion dynamics, and polarity by myosins IIA and IIB in migrating cells. J Cell Biol 176: 573-580.

Vicente-Manzanares M, Koach MA, Whitmore L, Lamers ML, Horwitz AF. 2008. Segregation and activation of myosin IIB creates a rear in migrating cells. J Cell Biol 183: $543-554$.

Vicente-Manzanares M, Ma X, Adelstein RS, Horwitz AR. 2009. Non-muscle myosin II takes centre stage in cell adhesion and migration. Nat Rev Mol Cell Biol 10: $778-790$.

Webb DJ, Parsons TJ, Horwitz AF. 2002. Adhesion assembly, disassembly and turnover in migrating cells-over and over and over again. Nat Cell Biol 4: E97-E100.

Webb DJ, Donais K, Whitmore LA, Thomas SM, Turner CE, Parsons JT, Horwitz AF. 2004. FAK-Src signalling through paxillin, ERK and MLCK regulates adhesion disassembly. Nat Cell Biol 6: 154-161.

Worthylake RA, Lemoine S, Watson JM, Burridge K. 2001. RhoA is required for monocyte tail retraction during transendothelial migration. J Cell Biol 154: 147-160.

Wozniak MA, Modzelewska K, Kwong L, Keely PJ. 2004. Focal adhesion regulation of cell behavior. Biochim Biophys Acta 1692: 103-119.

Xu W, Baribault H, Adamson ED. 1998. Vinculin knockout results in heart and brain defects during embryonic development. Development 125: 327-337.

Xu J, Wang F, Van Keymeulen A, Herzmark P, Straight A, Kelly K, Takuwa Y, Sugimoto N, Mitchison T, Bourne
HR. 2003. Divergent signals and cytoskeletal assemblies regulate self-organizing polarity in neutrophils. Cell 114: $201-214$.

Yamada KM, Geiger B. 1997. Molecular interactions in cell adhesion complexes. Curr Opin Cell Biol 9: 76-85.

Yamaguchi H, Condeelis J. 2007. Regulation of the actin cytoskeleton in cancer cell migration and invasion. Biochim Biophys Acta 1773: 642-652.

Yamaguchi H, Lorenz M, Kempiak S, Sarmiento C, Coniglio S, Symons M, Segall J, Eddy R, Miki H, Takenawa T, et al. 2005. Molecular mechanisms of invadopodium formation: The role of the N-WASP-Arp2/3 complex pathway and cofilin. J Cell Biol 168: 441-452.

Yoo S, Deng Q, Cavnar P, Wu Y, Hahn KM, Huttenlocher A. 2010. Differential regulation of protrusion and polarity by $\mathrm{PI}(3) \mathrm{K}$ during neutrophil motility in live zebrafish. Dev Cell 18: 226-236.

Yoshigi M, Hoffman LM, Jensen CC, Yost HJ, Beckerle MC 2005. Mechanical force mobilizes zyxin from focal adhesions to actin filaments and regulates cytoskeletal reinforcement. J Cell Biol 171: 209-215.

Yu DH, Qu CK, Henegariu O, Lu X, Feng GS. 1998. Proteintyrosine phosphatase Shp-2 regulates cell spreading, migration, and focal adhesion. J Biol Chem 273: 2112521131.

Zaidel-Bar R, Geiger B. 2010. The switchable integrin adhesome. J Cell Sci 123: 1385-1388.

Zaidel-Bar R, Cohen M, Addadi L, Geiger B. 2004. Hierarchical assembly of cell-matrix adhesion complexes. Biochem Soc Trans 32: 416-420.

Zaidel-Bar R, Milo R, Kam Z, Geiger B. 2007. A paxillin tyrosine phosphorylation switch regulates the assembly and form of cell-matrix adhesions. J Cell Sci 120: 137-148.

Zaman MH, Kamm RD, Matsudaira P, Lauffenburger DA. 2005. Computational model for cell migration in threedimensional matrices. Biophys J 89: 1389-1397.

Zaman MH, Trapani LM, Sieminski AL, Mackellar D, Gong H, Kamm RD, Wells A, Lauffenburger DA, Matsudaira P. 2006. Migration of tumor cells in 3D matrices is governed by matrix stiffness along with cell-matrix adhesion and proteolysis. Proc Natl Acad Sci 103: 10889-10894.

Zaman MH, Matsudaira P, Lauffenburger DA. 2007. Understanding effects of matrix protease and matrix organization on directional persistence and translational speed in three-dimensional cell migration. Ann Biomed Eng 35: 91-100.

Zamir E, Geiger B. 2001. Components of cell-matrix adhesions. J Cell Sci 114: 3577-3579.

Zhang X, Jiang G, Cai Y, Monkley SJ, Critchley DR, Sheetz MP. 2008. Talin depletion reveals independence of initial cell spreading from integrin activation and traction. Nat Cell Biol 10: 1062-1068.

Zhong C, Chrzanowska-Wodnicka M, Brown J, Shaub A, Belkin AM, Burridge K. 1998. Rho-mediated contractility exposes a cryptic site in fibronectin and induces fibronectin matrix assembly. J Cell Biol 141: 539-551. 